\title{
Short-term visual deprivation and the critical flicker frequency
}

\author{
D. W. HARPER and J. P. ZUBEK \\ University of Manitoba, Winnipeg, Canada RST 2N2
}

\begin{abstract}
An experiment is described in which the CFF was determined before and after $3 \mathrm{~h}$ of either visual deprivation (darkness) or a confined control condition. Results indicated no significant differences between the two groups and did not support an earlier finding of improved performance after $3 \mathrm{~h}$ of visual deprivation. The hypothesis that expected duration of deprivation accounts for the apparent discrepancy in results is not supported, but the results are consistent with the argument that the previously observed improvement in CFF following $3 \mathrm{~h}$ of visual deprivation was due to an inadvertently induced state of auditory deprivation.
\end{abstract}

Schultz's theory of sensoristasis (1965) predicts that conditions of lowered sensory variation will lead to a general enhancement of sensitivity. This state of hypersensitivity is said to occur through the mediation of the ascending reticular activating system (ARAS), a neural network believed to control general cortical arousal (see, for example, Lindsley, 1961). Investigations measuring sensitivity in several modalities before and after a 1 . week period of visual deprivation have usually supported Schultz's prediction (Duda \& Zubek, 1965; Pangman \& Zubek, 1972; Schutte \& Zubek, 1967; Zubek, Flye, \& Aftanas, 1964; Zubek, Flye, \& Willows, 1964).

Less support exists for the idea that sensoristasis occurs within the deprived visual modality. Duda (1965) found no changes in the critical flicker frequency (CFF) following a 1-week period of exposure to darkness. However, Gibby, Gibby, and Townsend (1970) reported a substantial (about $2 \mathrm{cps}$ ) improvement in CFF following just $3 \mathrm{~h}$ of either darkness or a ganzfeld condition. In order to test the hypothesis that this apparent discrepancy in results was due to the different durations of deprivation employed, Harper and Zubek (in press) have recently completed a study which charted the temporal course of changes in the CFF during 1 week of visual deprivation. The CFF was obtained at $0,3,6,9,15$, $24,48,72,120$, and $168 \mathrm{~h}$ of darkness, a ganzfeld condition, or a confined control condition. No significant changes in CFF were found in any group.

A careful look at the procedures employed by Gibby et al. (1970) reveals a possible reason for the observed improvement in CFF. Subjects in the two experimental groups (but not in the control group) were required to wear padded earphones during confinement (Gibby, 1966, p. 25). It is probable that the earphones, together with the experimenter's failure to provide auditory stimulation, inadvertently created a condition of auditory deprivation. It is possible that auditory rather than

Alexander W. Pressey sponsors this paper and takes full editorial responsibility for its contents. visual deprivation caused the changes in CFF observed by Gibby et al. This interpretation is made tenable by a recent report indicating that auditory deprivation does lead to improved CFF values (Bross \& Zubek, 1975).

Another, as yet untested, possibility exists that may explain the differences between our results and those of Gibby et al. Although both studies determined the CFF after $3 \mathrm{~h}$ of visual deprivation, the subjects of Gibby et al. knew that they would be released from their confinement after $3 \mathrm{~h}$, while the subjects of Harper and Zubek (in press) knew that they would be confined for 7 days. There is some evidence that "expectancy" concerning the duration of deprivation can determine the responses to sensory deprivation. Zubek, Shephard and Milstein (1970), for example, found that the temporal course of slowing of brain alpha-wave activity was related to expected duration of sensory deprivation.

It is possible that the discrepancy between the findings of Gibby et al. (1970) and those of Harper and Zubek (in press) is due to the different expectancies of the subjects in the two studies. The present study, then, was designed to induce the same "expectancy" as that of the subjects of Gibby et al., while avoiding the possible confounding variable of auditory deprivation.

\section{METHOD}

\section{Subjects}

The subjects were 28 male university students who volunteered to wear a blindfold over both eyes for a period of $3 \mathrm{~h}$. They were subdivided randomly into a control and experimental group. All of the volunteers were paid for their participation in the experiment.

\section{Deprivation Procedure}

The subjects were required to live, in groups of two, for $3 \mathrm{~h}$ in a furnished windowless room $(3.45 \mathrm{~m} \mathrm{x} 2.77 \mathrm{~m})$ which contained a small sofa, chairs, a radio, and brightly colored pictures on the walls. They were free to move about their living quarters and were encouraged to converse with each other and to listen to the radio.

During the 3-h period, subjects in the experimental group wore a black opaque mask over both eyes. Periodic checks were 
made to insure that there were no light leaks. The vision of the confinement control group was not restricted. However, to provide a living condition somewhat similar to that of the experimental group, they were not permitted to read.

\section{Apparatus and Test Procedures}

The monocular CliF of each subject was determined before and after $3 \mathrm{~h}$ of confinement. Wach test session was preceded by $20 \mathrm{~m}$ of binocular dark adaptation for the control subjects. Since the subjects wearing the black mask were in constant darkness for $3 \mathrm{~h}$, the dark adaptation procedure was only necessary at the beginning of the experiment for these subjects. Vach test session was preceded by the ingestion of a sweet chocolate bar to control for possible effects of changes in blood sugar level on the Clil: Initial testing began between 8:30 a.m. and 10:00 a.m. Subjects were tested in a constant order, with each subject's testing time not varying by more than $5 \mathrm{~min}$ on the successive occasions. The measurements were taken in a room adjacent to the living quarters.

The stimulus consisted of a white light which was presented monocularly by a cold cathode modulating lamp (Sylvania, Type $R 1131 \mathrm{c}$; crater diam $=.236 \mathrm{~mm}$ ) mounted at the rear of a standard viewing chamber (Lafayette, Model 1202c). The angle subtended by the centrally fixated stimulus was $2 \mathrm{deg} 10 \mathrm{~min}$, a value assuring full foveal stimulation. The flicker generating apparatus (Grason-Stadler, Model E622) was set at a light-dark ratio of .50 and a lamp current reading of $22.6 \mathrm{~mA}$. Eight trials, each separated by a 5 -sec intertrial interval, were presented to the preferred eye of one half of the subjects and to the nonpreferred eye of the other half. The descending method of limits was used with initial stimulus presentation above fusion. The subject's task was to report the first indication of a flickering sensation. The arithmetic mean of these eight trials was taken as the descending $\mathrm{CI} F \mathrm{~F}$ threshold for each subject.

Visual preference was determined by a special viewing device-the R.O. Gulden 17. Since the data indicated the presence of a similar proportion of right-eye- and lefteye-preferring subjects in all three groups, the results from the two eyes were pooled for purposes of statistical analysis.

\section{RESULTS}

The mean change in CFF from baseline was $+.08 \mathrm{cps}$ for the control group and $-.341 \mathrm{cps}$ for the experimental group. For statistical purposes a comparison of the mean pre-post difference scores of the experimental and control groups was performed by means of a $t$ test. Results indicated that the observed difference between the groups was not significant $(t=1.09, \mathrm{df}=26$, $\mathrm{p}>$.05).

\section{DISCUSSION}

The results of the present investigation clearly support the previous findings of Duda (1965) and those of Harper and Zubek (in press), both of which found no change in the CFF during 1 week of visual deprivation. The present results do not, however, concur with those of Gibby, Gibby and Townsend (1970), who found a significant increase in the CIF following $3 \mathrm{~h}$ of visual deprivation, the same duration as employed in the present study.
The hypothesis that the expected duration of visual deprivation accounted for the discrepancy in previous results was not supported in the present study. The best explanation of the anomalous results of Gibby et al. appears to be that inadvertent auditory deprivation led to an elevated CFF.

It can now be concluded with some confidence that visual temporal acuity, as measured by the CFI: is not affected by (up to) a 1-week period of visual deprivation. This finding constitutes a major exception to Schultz's prediction of generalized improvement in sensitivity which should result from sensory deprivation. Should subsequent research establish the generality of this exception (c.g., by cmploying other indices of visual sensitivity and by assessing auditory sensitivity in response to auditory deprivation), the theory of sensoristasis would be in need of considerable revision.

\section{REFERENCES}

Bross, M. \& ZuBex, J. P. Effect of prolonged auditory deprivation on the critical flicker frequency. Canadian Journal of Psychology, 1975, 29, 341-347.

DuDA, P. Auditory sensitivity after prolonged visual deprivation. Unpublished Master's thesis, University of Manitoba, 1965.

DudA, P., \& ZUBEx, J. P. Auditory sensitivity after prolonged visual deprivation. Psychonomic Science, 1965, 3, 359-360.

GrBBy, R. G. JR. The effects of visual restriction on visual and auditory discrimination. Unpublished doctoral dissertation. Catholic University of America. 1966.

Gibby, R. G., JR., Gibby, R. G., \& Townsend, J. C. Short-term visual restriction in visual and auditory discrimination. Perceptual and Motor Skills, 1970, 30, 15-21.

Harper, D. W., \& Zubex, J. P. Changes in critical flicker frequency during prolonged visual deprivation. Perception \& Psychophysics, in press.

Lindsuey, D. B. Common factors in sensory deprivation, sensory distortion and sensory overload. In $\mathbf{P}$. Solomon, $\mathbf{P}$. Kubzansky, P. Leiderman, J. Mendelson, R. Trumbull, \& D. Weller (Eds.), Sensory deprivation. Cambridge: Harvard University Press, 1961. Pp. 174-194.

Pangman, C. H., \& Zubex, J. P. Changes in auditory fusion frequency during prolonged visual deprivation. Perceptual and Motor Skills, 1972, 11, 172-174.

SCHUTTE, W., \& ZUBeK, J. P. Changes in olfactory and gustatory sensitivity after prolonged visual deprivation. Canadian Journal of Psychology, 1967, 21, 337-345.

SCHULtz, D. P. Sensory restriction: Effects on behavior. New York: Academic Press, 1965.

Zubek, J. P., Flye, J., \& Aftanas, M. Cutaneous sensitivity after prolonged exposure to unpatterned light. Science, 1964, 144, 1591-159.3.

Zubex, J. P., Flye, J., \& Willows, D. Changes in cutaneous sensitivity after prolonged exposure to unpatterned light. Psychonomic Science, 1964, 1, 283-284.

Zubex, J. P., Shephard, J. M., \& Milstein, S. L. EEG changes after 1, 4, and 7 days of sensory deprivation: A cross-sectional approach. Psychonomic Science, 1970, 19, 67-68.

(Received for publication February 26, 1976.) 